\title{
À MODA DA PATROA: o labor segundo o trabalho doméstico remunerado no Brasil.
}

\author{
Willians Alexandre Buesso da Silva ${ }^{1}$
}

\section{Resumo:}

O trabalho doméstico remunerado no Brasil tem se tornado objeto de estudo frequente nas Ciências Sociais. As categorias de análise gênero, raça e classe social são as abordagens mais recorrentes para falar sobre sua condição de trabalho, historicidade e questões pertinentes aos seus dados no passado e presente. A partir dos anos 2000 verificou-se uma elevada taxa no aumento de trabalhadoras domésticas sem carteira assinada, a mudança corre em direção contrária aos avanços jurídicos conquistados recentemente com a Emenda Constitucional 72a de 2013, a qual garante todos os direitos previstos na Consolidação das Leis Trabalhistas de 1943. O seguinte artigo discute sobre essa mudança no trabalho doméstico remunerado a partir da pesquisa de campo realizada em 2016 na cidade de Marília (SP) com empregadas, diaristas e empregadores(as). A partir dos dados levantados, verificou-se que problemas estruturais como a divisão sexual do trabalho doméstico tende a repercutir sobre a profissão quando oferecida como serviço, sendo delineada principalmente por indicadores sociais de gênero.

Palavras-Chave: Empregadas domésticas; Diaristas; Gênero; Família

\begin{abstract}
:
The Domestic Work in Brazil has become the subject of frequent study in the Social Sciences. The categories of gender, race, and social class analysis are the most recurrent approaches to talking about their work condition, historicity, and issues relevant to their data in the past and present. Since the 2000s there has been a high rate of increase in the number of domestic workers without a formal contract, the change runs counter to the legal advances recently achieved with the Constitutional Amendment 72 of 2013, which guarantees all the rights provided for in the Consolidation of Laws. The following article discusses this change in paid domestic work from field research conducted in 2016 in the city of Marília (SP) with maids, day laborers and employers. Based on the data collected, it was found that structural problems such as the sexual division of domestic work tend to have repercussions on the profession when offered as a service, being outlined mainly by gender social indicators.
\end{abstract}

\footnotetext{
${ }^{1}$ Mestre em Ciências Sociais pelo Programa de Pós Graduação da Universidade Estadual Paulista Júlio de Mesquita Filho - Campus de Marília, na linha 2 - Cultura, Memória e Identidade. Pesquisa sobre Trabalho Doméstico remunerado no Brasil, e em especial na cidade de Marília (SP). Graduado em Ciências Sociais pela mesma Universidade. Atualmente trabalha como professor efetivo de Sociologia da Rede Pública de Ensino do Estado de São Paulo. Tem experiência na área de Educação de Sociologia e Ensino de História pelas Imagens, ambos relacionados a projetos vinculados a Faculdade de Filosofia e Ciências do Campus Marília. E-mail: wabsilva@gmail.com
} 
Keywords: Domestic Housework; Maids; Housecleanners; Gender. 


\section{Introdução}

O labor, sinônimo de trabalho em latim (AULETE, 2011, p.834), é tema chave dentro das Ciências Sociais, o conceito foi apropriado aqui a partir do texto "A Condição Humana" (2010) de Hannah Arendt, em seu terceiro capítulo quando a autora destrincha o conceito de trabalho desde a Grécia Antiga. Em uma de suas passagens, chama a atenção à contextualização de quem eram os chamados 'criados domésticos' (ARENDT, 2010, p.107), e qual sua função social. Para os donos de escravos domésticos, sua função nada mais era do que libertá-los do tempo gasto com a própria manutenção da vida humana, assim livres, possuíam o tempo necessário para produzirem. A afirmação introduz nosso tema, o trabalho doméstico remunerado e suas definições de tempo e trabalho.

O motivo principal do interesse pelo tema da pesquisa foi amadurecido durante o processo de Iniciação Científica, mas se deu pelo fato de enquanto estudante de Ciências Sociais, em 2008, ter presenciado a experiência de ver uma ente familiar muito próxima, trabalhar como empregada doméstica por um curto período de tempo para quitar uma dívida pendente com uma conhecida de bairro. Sobre esta condição, indaguei como uma amizade entre duas mulheres poderia ser substituída pela relação de trabalho em que uma delega à outra a manutenção de sua casa.

A partir deste fator, passei a me debruçar mais sobre o tema do trabalho doméstico e a condição de empregadas domésticas no Brasil, motivo este que pode suscitar inúmeras discussões, o que, no entanto, nos limitamos aqui a tratar alguns de seus aspectos que serão destaque neste texto.

O foco principal desse artigo está em um dos desdobramentos da pesquisa realizada durante a Iniciação Científica durante o ano de 2012, financiada pela FAPESP - Fundação de Amparo a Pesquisa do Estado de São Paulo - intitulada "Em pratos limpos: uma análise sobre o trabalho doméstico na cidade de Marília (SP)", e de Mestrado em 2016 com o projeto "Serviço que nunca acaba: trabalho doméstico remunerado na cidade de Marília (SP)" parcialmente financiado pela CAPES - Coordenação de Aperfeiçoamento de Pessoal de Nível Superior -, ambos voltados para o trabalho doméstico remunerado, feito na cidade de Marília (SP).

A primeira visita a campo em 2012 foi marcada pela incipiência da relação com os contatos para entrevistas, pois pelo fato de não haver uma lista prévia de possíveis nomes para 
ser abordados, inicialmente tínhamos selecionamos durante esse início de pesquisa durante a Graduação - que durou aproximadamente três meses -, três bairros de acordo com sua localização: no centro da cidade de Marília (SP); outro em uma área nobre com acesso à serviços comerciais e assistência pública; e por fim, uma região distante do centro, considerada periférica dentro do perímetro urbano.

Durante esta imersão em campo, um dos aspectos que ficou ressaltado foi o fato de ter encontrado muitas mulheres que já haviam tido o vínculo estável de empregada doméstica ou seja, trabalhar em uma "casa de família" -, e posteriormente, optar por organizar seu tempo e trabalho como diarista.

O termo "casa de família" foi recorrente no discurso de empregadas e diaristas, ele simboliza os laços que uma trabalhadora doméstica possui não devido ao vínculo empregatício, mas pela responsabilidade de submeter-se aos gostos, horários e costumes de uma casa. Como retrata Suely Kofes (2001, p.172), a profissão possui essa condição de domesticidade, o que significa tanto conviver com a intimidade familiar como pertencer a casa como um bem utilitário. Além de simbolizar o vínculo familiar, o termo também remete à questão da família como instituição ordenadora de nossa sociedade, item a ser discutido adiante com autores do pensamento social brasileiro.

Retratamos aqui o foco para o trabalho de diaristas neste artigo, pois quando houve o posteriormente o contato em 2016 com o campo, fomos ainda com a representação em mente da imagem de uma empregada aos moldes da primeira visita a alguns bairros de Marília em 2012, ou seja, uma mulher, uniformizada e com um vínculo familiar de longa data em uma casa.

Sendo assim, a Iniciação Científica nos proporcionou o contato com as duas situações de trabalho, houve tanto empregadas quanto diaristas, mas em número equânime. Todavia, não percebemos o discurso de empregadas que revelavam ter optado mudar a situação para melhor relação de trabalho. Por este motivo, apresentamos aqui este tema como uma novidade para o objeto estudado.

A cidade de Marília (SP), além de localizar a instituição onde foi realizada a pesquisa na Universidade Estadual Paulista/UNESP, nos serviu de base para questionarmos objetivos mais gerais de nossa pesquisa e da temática que vem ganhando espaço dentro das Ciências Sociais, assim como levantar algumas reflexões: O que muda de um regime de mensalista 
para diarista? Essa mudança está para todas as casas que possuem empregadas domésticas? Será que essas são mudanças que afetariam as representações do trabalho doméstico remunerado, seu vínculo, e condições de trabalho relacionado à sua historicidade?

Algumas dessas perguntas vão além do tema relativo ao trabalho doméstico em nosso país, pois serve como referência para falar sobre a sociedade brasileira, família e relações de trabalho pautadas na divisão por sexo.

\section{Trabalho doméstico no Brasil e seu perfil}

A profissão, representada como a área "serviço doméstico" para o IBGE (2016) tem servido como objeto de estudo em diferentes ângulos teóricos dentro das Ciências Sociais, os principais eixos circundam sobre as temáticas de gênero, raça e classe social no Brasil (AZEREDO, 2002; KOFES, 2001; BRITES; 2000; SAFFIOTI, 1978).

Gênero e raça chamam a atenção para os detalhes quanto ao trabalho doméstico por percebermos a maioria significativa de mulheres negras atuantes na profissão. A Pesquisa Nacional por Amostra de Domicílio (PNAD, 2011) realizada pelo IBGE - Instituto Brasileiro de Geografia e Estatística - revela que de um total de $92 \%$ de mulheres que atuam nesta categoria profissional, pelo menos $61 \%$ são mulheres negras. Por este motivo também, ao longo do texto nos referimos sempre no gênero feminino ao tratar o grupo atuante nessa área de serviço.

Sobre a condição de trabalho, dados do Departamento Intersindical de Estatística e Estudos Sócio-econômicos (DIEESE, 2012, p. 148), no artigo “O Emprego Doméstico nos anos 2000”, revelam que o serviço doméstico além de ser a área de ocupação que recebe o maior número de mulheres negras, entre as áreas de expressiva atuação feminina, está como uma das ocupações de menor rendimento salarial, mesmo diante dos outros setores, como o de comércio.

Entre os anos de 2005 e 2015 (IBGE, 2016), a taxa de 3,7\% de trabalhadores domésticos sem carteira assinada subiu para 13,4\%, evidenciando uma das áreas que menos apresenta formalização em suas relações contratuais. A mudança de mensalistas para diaristas de fato não está para todos, pois passa por diversas situações que vão além dos dados percebidos em campo. Todavia, dados estatísticos permitem inferir que mesmo assim, são transições em curso, continuam a ocorrer. 
A hipótese que suscitamos é de que essas e outras mudanças que vêm ocorrendo no Brasil estão relacionadas com as categorias de análise apontadas acima - além de classe gênero e raça dão caminhos para entender essa situação (HIRATA, 2014), e perceber quais as superações e persistências dentro de uma área de serviço pouco assistida juridicamente. Em complemento a essa situação, reconhecer a historicidade do trabalho doméstico no Brasil por ter seus efeitos sobre renda, condições de trabalho e seus reflexos quanto a rotina de trabalhadoras domésticas.

A compreensão dessas indagações passa pelo entendimento do que é o trabalho doméstico, seja ele remunerado ou não, o seu valor enquanto profissão e quais suas características enquanto função social. O tema também está atrelado a outras discussões mais amplas, como a maior presença de mulheres no mercado de trabalho, a divisão por sexo do trabalho realizado no ambiente doméstico e como o processo de delegação (HIRATA e KERGOAT, 2007) faz da trabalhadora doméstica responsável por obrigações não assumidas por famílias. O conceito calcado pelas sociólogas francesas Helena Hirata e Daniélle Kergoat resume-se no ato de casais não discutirem a divisão do trabalho doméstico e automaticamente responsabilizarem terceiros para essa demanda.

Esses e outros detalhes têm um impacto marcante sobre o tempo e noção de trabalho para diaristas, talvez uma noção que não tenha sido explorada ainda enquanto trabalho dentro das Ciências Sociais, mas corresponde às diferenças de subjetividades e valores simbólicos que refletem o dia a dia de mulheres.

Outro fato que acrescenta detalhe a esse argumento é o de que a legislação brasileira teve ao longo do século $\mathrm{XX}$ poucos avanços no quesito jurídico relacionado a profissão, a maior mudança sentida foi com a Proposta de Emenda Constitucional 72a (BRASIL, 2013), a qual estende os direitos e garantias trabalhistas previstos na Consolidação das Leis Trabalhistas de 1943 às empregadas domésticas, a regulamentação tardia da lei é reflexo do valor que a profissão possui no país.

Em meio a outras transições, o trabalho doméstico remunerado sempre esteve no fogo cruzado entre legalidade e informalidade nas relações contratuais. A História do trabalho doméstico enquanto profissão no Brasil é esclarecedora ao detalhar suas dificuldades em ser reconhecido enquanto uma área de serviço, a qual possui demandas, políticas públicas, e principalmente o valor simbólico e remunerado que possui. 
Trata-se de reconhecer a importância de papéis que em nossa sociedade passaram por uma construção histórica enquanto subalternos, assim como, serviram de base de famílias, grande representante de uma instituição formadora de valores exportada aos moldes da nobreza européia portuguesa e aristocrática.

Antes de tratar propriamente a historicidade do trabalho doméstico no Brasil, é importante salientar o poder da família com traço característico da formação da sociedade brasileira. Autores do pensamento social brasileiro, de acordo com sua época e perspectivas de pesquisa (FREYRE, 2006; DAMATTA, 1997; 1986; 1985; HOLANDA, 1982, DUARTE, 1939) versaram sobre o tema e definiram alguns aspectos importantes para entender passado e presente quanto a relação íntima entre afazeres domésticos e ambiente familiar.

Entre as principais contribuições dos autores, está a formação da sociedade brasileira estruturada no processo de colonização portuguesa a partir da importância da família como sustentáculo principal das relações sociais dentro e fora do ambiente doméstico, fato que constata a realidade de que, família e Estado formaram no período colonial uma dualidade contraposta, na celebre polaridade entre público e privado, como cita Sérgio Buarque de Holanda em Raízes do Brasil:

\begin{abstract}
(...)A nostalgia dessa organização compacta, única e intransferível, onde prevalecem necessariamente as preferências fundadas em laços afetivos, não podia deixar de marcar nossa sociedade, nossa vida pública, todas as nossas atividades. Representando, como já se notou acima, o único setor onde o princípio de autoridade é indisputado, a família colonial fornecia a ideia mais normal de poder, da respeitabilidade, da obediência e da coesão entre os homens. O resultado era predominarem, em toda a vida social, sentimentos próprios à comunidade doméstica, naturalmente particularista e antipolítica, uma invasão do público pelo privado, do Estado pela família.(1982, p.49)
\end{abstract}

Além da força do particular sobreposta à esfera pública, Holanda também ressalta a importância das "virtudes senhoriais" (1982, p.50) em que os brasões familiares tinham um peso maior que títulos de honra. Nesse contexto, servir nunca foi sinônimo de prosperidade na sociedade aristocrática, assim como ter empregados dentro de casa passou pelo crivo não só da necessidade, como também do status.

A família, portanto, representava o que Nestor Duarte em “A ordem privada e a Organização Nacional" (1939) chamou de "transplantação" (1939, p.126) do ocidente europeu para território nacional, em que o poder do Estado entra em conflito com as relações pessoais. 
Os dois autores procuram retratar de que maneira os costumes na vida privada tendiam a organizar o espaço público, e é a partir dessa constatação que nos ajuda a entender algumas dualidades como "mando-obediência", "patrão-empregado" e "esnobe-humilde" se estruturam como assimetrias em nossa sociedade, tão evidente no trabalho doméstico oferecido a terceiros como um serviço, como veremos durante as entrevistas.

Uma atualização desses traços da sociedade brasileira é representado pelo trabalho de Roberto DaMatta em “Carnavais, Malandros e Heróis” (1997) ao destrinchar estratégias que tentam driblar as hierarquias sociais de um sistema que ora se apresenta como horizontal em suas oportunidades, ora é carregado de pessoalidade nas relações dentro do espaço público. O exemplo tomado pelo autor para citar essa característica cultural está na expressão "sabe com quem está falando?”, em que o autor cita:

\begin{abstract}
(...)O sistema iguala num plano e hierarquiza no outro, o que promove uma tremenda complexidade classificatória, um enorme sentimento de compensação e complementaridade, impedindo certamente a tomada de consciência social horizontal. Sendo assim, é facilitada a tomada de consciência social vertical, com o empregado identificando-se em certas ocasiões com o seu patrão, a empregada com a casa onde trabalha, o trabalhador com a empresa que o emprega e a empresa e os empresários com certos órgãos do Estado, pois no Brasil tudo indica que o Estado é o domínio responsável pela totalização de todo o sistema na sua vertente formal e acabada." (1997,p.193-194)
\end{abstract}

Não por acaso, o autor utiliza diversas vezes a condição de empregadas doméstica ao falar de relações servis. Em “O que faz do brasil, Brasil?” (1986, p.20) o autor ressalta que, "diferentemente de outros países modernos, aqui no Brasil as casas possuem serviçais que, em certo sentido, lhes pertencem. E cuida-se de seu bem-estar porque a ideia de residência é um fato social totalizante, conforme diria Marcel Mauss."

A pessoalidade, associada ao peso que a família de grande poder aquisitivo possuiu e se mantém até os dias de hoje, é combinado com a ideia de que servir é responsabilidade de outros entes da casa que não aqueles que são de fato membros familiares, por este motivo, vemos a discussão sobre o trabalho doméstico importante para desnaturalizar sua presença em determinadas casas. Sua história também apresenta aspectos que contribuem para esse processo de entendimento da realidade.

Historicamente, o trabalho doméstico esteve relacionado às mulheres, entre negras e brancas, pobres ou ricas, o esforço realizado é que diferenciava as duas camadas sociais, entre senhores e negros submetidos ao regime escravo. Até metade do século XIX, o trabalho 
doméstico enquanto obrigação era realizado no Brasil majoritariamente por mulheres negras em regime de escravidão, isso quer dizer que a Casa Grande relatada por Gilberto Freyre (2006), tinha como principais empregados a população escravizada.

Para o período, o título de "criadas", como observa Sandra Graham (1992), representa muito mais qual a condição de trabalho das mulheres em questão do que a ideia de uma profissão reconhecida e assalariada. A autora também se apropria do binômio a "casa" e a "rua" adotado por Roberto DaMatta (1985) em obra homônima ao termo, para falar tratar a relação "mando-obediência" entre criadas e seus patrões.

Apesar da relação de subserviência dessas trabalhadoras, Maria Odila Leite da Silva Dias (1984) reconhece no trabalho de mulheres cativas dentro do espaço doméstico, a possibilidade de estar próxima de seus patrões, a confiança de vender quitutes em espaços públicos e gerar rendimentos extras para além da rotina da casa é exemplo desta condição. O trabalho dentro da casa e sua extensão para o espaço público sempre passou pela autoridade de patrões, mas diferenciava-se da lavoura

A partir da segunda metade do século XIX é possível observar registros de trabalho de empregadas domésticas. Lorena Telles (2011) apresentou a partir de registros policiais a presença de empregadas como trabalhadoras que circulavam nas emergentes metrópoles concentradas nas áreas urbanas do Brasil, como Rio de Janeiro, Salvador, e em especial, São Paulo, foco de sua pesquisa. O controle de ex-cativas e mulheres pobres (TELLES, 2011, p.44), no entanto, se desenhava mais como uma mudança dos métodos de disciplinamento à recente alforria do que uma legalização da profissão.

Portanto, apesar da historicidade do trabalho doméstico ser esparsa, não passa despercebido em nossa historiografia, a leitura desses textos também ressaltam a importância em contribuir para a "História das Mulheres" (PEDRO \& SOIHET, 2007, p. 284). Antes, a História marcada pelo homem enquanto sujeito histórico universal, tornava obscura a participação de mulheres nos processos históricos, assim como vinculava os acontecimentos e mudanças aos grandes indivíduos e batalhas. As mudanças ocorridas na historiografia nos ano de 1980 (DIAS, 1983) ampliaram as discussões relativas às representações femininas e as narrativas, como também, alargou o campo de pesquisa para elementos antes desconsiderados enquanto fonte histórica, entre eles, a vida cotidiana como exemplo dos processos de transformação da realidade. 
Como atividade exercida dentro de um regime de trabalho forçado e dentro do ambiente familiar, a categoria passou aos poucos a ser reconhecida como serviço, mas mesmo assim, pouco remunerada. Contudo, muitas vezes seu vínculo com o passado pelo valor cultural que carrega, tanto de sua história quanto da relação com a família enquanto instituição formadora de valores culturais e sociais tem atravessado o limite temporal para entender condições atuais da profissão. Nesse sentido, a História não determina o presente, mas auxilia a sua compreensão.

Discutida a historicidade do objeto de pesquisa, entendemos que seja necessário distinguir entre o trabalho doméstico remunerado e o não-remunerado. $\mathrm{Na}$ literatura referente trabalho feminino (BRUSCHINI, 2006) há diferentes termos para atividades próximas, como exemplos, emprego doméstico e serviço doméstico se assemelham a trabalho doméstico remunerado, mas trabalho doméstico não-remunerado é reconhecido como de caráter privado, sem fins lucrativos, o que muitas vezes o leva a ser descaracterizado enquanto trabalho, mesmo que ele contribua diretamente para a economia da casa. A relação entre ambos está na definição conceitual de "trabalho reprodutivo":

(...)O 'trabalho reprodutivo' é aqui entendido como o trabalho da manutenção da vida e reprodução das pessoas, ou seja, aquele que envolve um conjunto de atividades realizadas na esfera privada e familiar sem as quais a reprodução humana não estaria assegurada, como o cuidado com os filhos e dependentes e as tarefas domésticas (limpeza da casa, preparo das refeições, etc.) 'Trabalho doméstico' não remunerado, 'cuidados' ou 'atividades/tarefas de manutenção da casa e dos filhos' têm aqui o mesmo sentido de 'trabalho reprodutivo', opondo-se ao trabalho produtivo, ou seja, aquele que resulta na produção de bens ou serviços com valor econômico no mercado, também chamado de 'trabalho remunerado' (ainda que possa não ser de fato remunerado). (ÁVILA\&FERREIRA, 2014, p.61)

Portanto, entre o trabalho não-remunerado e o remunerado, a atividade da manutenção da casa tem majoritariamente responsabilizado mulheres para este trabalho, a maneira como a sociedade trabalha e constrói as relações de gênero, como citou Joan Scott (1995) em seu texto clássico "Gênero: uma categoria útil de análise histórica” é perceptível ao compreender a associação entre demanda doméstica e mulheres.

O ponto de encontro da definição com o valor que o trabalho doméstico possui enquanto serviço remunerado, a partir da sua noção de tempo e espaço definido pelos entrevistados e a condição de diaristas em sua rotina, reside no fato de que historicamente mulheres assumem a responsabilidade doméstica (ÁVILA\&FERREIRA, 2014, p.18), 
contudo, desigualdades sociais fazem mulheres perceber a entrada no mercado de trabalho de maneiras distintas.

A autonomia financeira de mulheres que participam economicamente ativa no mercado de trabalho no século XX não foi acompanhada de uma mudança estrutural na relação com o trabalho doméstico. Para o caso de empregadas e diaristas, a função da manutenção da casa tanto sua, quanto de seus empregadores, faz dessa relação um nítido exemplo de como a manutenção da vida humana tem seu valor para outras atividades produtivas, todavia, as mudanças sentidas no regime de trabalho da profissão fazem perceber outros aspectos além do seu reconhecimento enquanto trabalho.

As mudanças na rotina de trabalho de empregadas domésticas para diaristas refletem o tempo da flexibilidade, mas concomitante à facilidade de empregadores contratarem sem nenhum vínculo um serviço fundamental para a 'liberdade de produzir' (ARENDT, 2010), esconde os efeitos sentidos pelo corpo e a subjetividade de trabalhadoras domésticas.

\section{Metodologia e Trabalho de campo}

A proposta metodológica do projeto teve como base outras etnografias com o trabalho doméstico (BRITES, 2000; KOFES, 2001), pois foi a partir do referencial teórico da Antropologia Interpretativa de Geertz (2012) que nos aproximamos das micro-relações características do trabalho doméstico e que fazem a manutenção de seu valor social e cultural enquanto profissão. Além dessa possibilidade de análise, o autor é reconhecido pela afinidade com História Cultural e a História Oral (BURKE, 2008, p.56) ao reconhecer na observação em campo, na oralidade e nas entrevistas uma possibilidade de conhecer o objeto em questão.

Quando abordamos o tema do trabalho doméstico tivemos a preocupação em salientar quais nossos pressupostos, os quais serão esclarecidos neste subitem. Assim como há diferentes interesses no tratamento de um mesmo objeto de estudo, envolver a relação entre empregadas e empregadores requer um posicionamento ético. Em campo, o interesse foi ouvir tanto empregadores(as) quanto empregadas, todavia, consideramos de suma importância perceber a ausência de representatividade política por parte de empregadas, fato este comprovado pela ausência de um sindicato na cidade de Marília (SP), o que nos levou a considerar com mais atenção o lugar do discurso das entrevistadas. 
A pesquisa de campo ocorreu durante o segundo semestre de 2016, na cidade de Marília interior do Estado de São Paulo. A cidade, fundada em 1929 (DELICATO, 2011), possui hoje de 216.745 habitantes (IBGE, 2017). Um dos principais logos da economia local é "a cidade dos alimentos", por abarcar diferentes setores alimentícios, sendo esse um dos motivos de possuir médio porte enquanto espaço urbano e suas regiões adjacentes pertencentes a seu distrito.

Apresentamos duas abordagens diferentes de bairros nesta pesquisa, todos são caracterizados por ser residencial, mas o que os diferencia são os acessos à serviços que eles possuem (comércio, assistência pública, entretenimento, lazer) e a proximidade com o centro urbano da cidade de Marília (SP).

O critério de escolha do bairro selecionado para a entrevista com empregadas e diaristas esteve relacionado diretamente com a condição econômica e perfil de trabalhadoras que citamos no começo deste texto. Não por acaso, a maior concentração de trabalhadoras domésticas que encontramos durante a pesquisa morando em um mesmo bairro tinha como característica ser um bairro popular, com pessoas de baixa renda, em que as casas possuem baixos aluguéis, quando não, são cedidas pela prefeitura.

O Parque das Vivendas está localizado na saída da cidade de Marília (SP) sentido Assis (SP), em uma região periférica. Ele existe a mais de 30 anos na zona oeste de Marília (SP), mas foi a partir da década de 2010 - segundo entrevistadas - que passou a ser incorporado ao espaço urbano, pois o processo de desfavelamento de uma antiga comunidade com o mesmo nome e idade do bairro deu corpo ao número de casas no local. $\mathrm{O}$ acordo foi feito com o poder municipal, sendo as prestações do imóvel de acordo com o orçamento familiar de cada família da antiga comunidade. Além das antigas casas já existente no local e as habitações construídas pela prefeitura, o bairro possui algumas pequenas propriedades rurais de produção de subsistência, hortaliças e pouca pecuária.

Já os bairros abordados durante as entrevistas com empregadores não houve uma préseleção, e sim um contato prévio estabelecido antes mesmo de pensarmos em abordar casas à primeira vista. A situação ocorreu após percebermos a dificuldade de conseguir conversar com empregadores sem uma intermediação. De certa maneira, o dado revela como o trabalho doméstico feito enquanto serviço faz parte da ordem de empregadores(as) da porta para dentro de casa, como um assunto privado. 
Os bairros abordados nesta etapa da entrevista - Barbosa e Tangará - são tanto comerciais quanto residenciais, o que os caracteriza como diferentes do Parque das Vivendas é o fato de ser áreas nobres da cidade, com os moradores que possuem alto poder aquisitivo.

Ao todo foram quatro entrevistas com empregadas/diaristas e quatro entrevistas com empregadores, sendo dois homens e duas mulheres. Apesar do número restrito de entrevistas para respeitar os limites e objetivos da pesquisa, encontramos em quarenta casas abordadas no Parque das Vivendas dentro do segmento selecionado - o que corresponde aproximadamente a uma rua de duas quadras - o total de vinte mulheres que trabalhavam na área de serviço pesquisado ou relacionado a ela (como cozinheira, babá e ajudante de serviços gerais).

Para as entrevistas em campo, o critério de escolha foi alinhado com a possibilidade dada pelos entrevistados de um horário e local para se fazer a pesquisa. No caso do Parque das Vivendas as entrevistas ocorreram com mais facilidade, sem tantos empecilhos para chegar até as mulheres entrevistadas, já nos outros bairros em que houve a entrevista com empregadores, um horário e data com antecedência razoável foram marcados, assim como um pré-projeto da pesquisa foi enviado antes que ocorresse qualquer exposição da vida íntima desses participantes.

A imersão do pesquisador em campo também é parte dos resultados obtidos em campo. Como apontou Hermano Vianna (1988, p.15) ao trabalhar com o 'mundo do funk carioca', o autor destaca que as roupas podem ser as mesmas dos nativos pesquisados, assim como as gírias e hábitos, mas a cor da pele marca o distintivo social de estar em um local diferente ao seu. Neste caso, ampliaria as diferenças ao concluir que um homem entrevistando mulheres tem seus efeitos específicos no trato da questão do trabalho doméstico.

Por esse motivo, enquanto abordávamos casas e famílias, a procura por empregadas domésticas e diaristas foi paralela ao respeito em não invadir espaços que possuem seus valores, independente de nossas hipóteses, não pretendíamos em campo interferir naquela realidade sem antes entendê-la.

Como forma de estruturação do texto, iremos apresentar falas de dois entrevistados(as) representados por "A" e "B" direcionado para temáticas específicas: qual o valor do trabalho para cada um deles; como o tempo é percebido por esses entrevistados(as); qual a função de uma diarista; e quais as mudanças de mensalista para diarista. Ao final das falas iremos revelar o sexo de cada participante e retomar a hipótese a partir dos argumentos levantados. 


\section{Entrevistas}

\section{O valor do trabalho doméstico}

A: [...] na verdade você não senta junto na mesa pra comer, tem que comer na cozinha, porque querendo ou não você é uma serviçal, e se tem que saber isso por mais que você se apegue, nossa eu...quando sai de lá fiquei bastante chateada, porque eu gostava muito do menininho, o menininho ficou doente, ela teve que ir atrás de mim...O menino saia da casa dela e ia bate na minha casa, que era no mesmo bairro...Ela morava ali no [Rua] Professor António Reginato, na chácara, e eu morava na favelinha pra baixo da chácara...

A: [...] elas não aceitam, elas acham que você faz um serviço como outro qualquer...Então elas mandam a fixa embora, e contrata a diarista que fica mais fácil...Depois elas contratam uma diarista por semana...Porque eu intercalo casa...só tem uma que eu trabalho toda semana, as outras três eu intercalo, semana sim, semana não...

B: É a necessidade! É o trabalho! Agora, tem pessoas que, por exemplo, eles não podem ter. Por que? Eles já não ganham o suficiente nem pra sua subsistência, né? Então, espera aí, então como ele vai ter? Mas ai, muito bem. É o seguinte! Esses trabalhos que teoricamente são um pouco menos remunerados, as pessoas trabalham um pouco menos horas [esses que não podem ter empregada]. Por exemplo, se eu hoje, for tirar parte das minhas horas de trabalho daqui, da minha função principal para ir para a minha função secundária, o custo pra mim não vale a pena... Agora, pode chegar o momento em que, que o ganho seu, no seu trabalho principal não é o suficiente pra você pagar alguém pra fazer pra você, é melhor você fazer! Tudo depende de quanto custa! A minha hora trabalhada lá, custa menos do que aqui.

\section{O tempo do trabalho}

A: Você tem que trabalhar das $8 \mathrm{~h}$ da manhã e sair $18,19 \mathrm{~h}$ da noite...E se você pedir mais não pagam...Então você não tem muita opção, ou você recebe $\mathrm{R} \$ 100,00$ ou você não recebe nada...Que nem, eu trabalho numa casa que a mulher me paga $\mathrm{R} \$ 80,00$, só que ela ajuda a fazer a faxina ${ }^{2}$..

A: Aqui eu faço a hora que eu quero...que nem, eu tava deitada até agora assistindo televisão. Lá não! Lá eu tenho que entrar no horário certo e eu tenho que entregar o serviço. Eu não posso sentar, eu não posso assistir uma Tv, eu não posso muitas vezes nem ouvir um rádio. Então é assim, aqui é minha casa, o dia que eu quiser fazer, eu faço, o dia que eu não quiser fazer eu passo uma vassoura, eu arrumo as camas e vou curtir eles, brincar e tudo...

A: É! E lá não, você tem que fazer... Você é paga pra isso... Você não pode sentar para assistir uma televisão, você não pode sentar na mesa pra comer com eles, você tem que sentar na área ou na cozinha.

B: Na verdade eu acho o seguinte, eu acho que essa história de ter a diarista, ela vai muito de encontro ao fato de não só de você não querer fazer, e sim de você não poder fazer! Então, por exemplo, eu hoje, eu não posso fazer. Mesmo que eu quisesse. Ta? Por que? O número de

2 "Faxina", assim como "Casa de família", é outro termo recorrente na fala de empregadas domésticas e diaristas. O cronograma da semana de uma diarista é dividido em "faxinas", cada casa representa um serviço oferecido. Quando uma mensalista resolve fazer hora extra aos sábados, ela diz fazer "faxina" aos finais de semana. 
horas que eu necessito para o meu trabalho, não dá espaço para que eu faça alguma coisa do tipo “Ah! Vou lavar roupa, é fácil lavar roupa, é só colocar na máquina!”. Mas eu não tenho este tempo! Então o tempo que eu tenho hoje, é melhor me dedicar... Porque não deixa de ser o trabalho doméstico, seja da diarista, seja da pessoa, não deixa de ser um trabalho! Então se a pessoa não tem uma diarista, ela faz o trabalho. Ela dividi o dia dela enquanto: lazer, trabalho e repouso! Mais ou menos isso, certo? Então na verdade ela tem trabalho ou repouso...seja o trabalho doméstico, ou o trabalho fora de casa...Então, em vez de eu fazer esse trabalho dentro de casa, eu faço este trabalho fora de casa, e dou a oportunidade de outra pessoa ter este trabalho. Acho que é por aí que eu vejo a questão...

B: O trabalho que eu dedico para a casa, por dia, eu dedico entre meia-hora à 1 hora. Por que não tem fazer compra? Não tem que trocar uma lâmpada? Não tem que estender uma toalha? Coisas que podem acontecer... Ah! Se você fez a compra, você tem que chegar lá e arrumar a compra! Eu não largo lá para ela fazer! Por exemplo, ela lavou a roupa, ai eu peço para ela não guardar, porque ai eu guardo onde eu quero, porque se não ela guarda do jeito dela, não é do meu...Então, ou seja, no mínimo, por dia, eu dedico ai de 30 minutos à 1 hora, no mínimo, pra esse trabalho. E o outro trabalho, seja pensando, seja na rua, seja fazendo, seja o que for, da ai no mínimo umas 13 à 14 horas.

B: Mas eu digo, tem muitas funções que a pessoa acaba fazendo algo fora daquele momento, é o meu caso - por exemplo - e de n outros casos. Então a pessoa fica assim, a hora que sobra, que hora sobra? Se você também for fazer o trabalho doméstico, também vai ser mais horas... Então sobra cada vez menos horas para que você tenha o seu repouso!

\section{A função de uma diarista}

A: [Os filhos dos patrões para uma empregada doméstica] É como se fosse seu filho, não tem essa divisão, você está lavando a louça o filho berra, você vai lá e acode...o filho chora, você vai lá e acode...outra hora eles estão atrás do sê, grudado nas suas pernas...Então você acaba fazendo as duas coisas ao mesmo tempo...E você ta numa casa que tem criança, não tem como dividir...limpar a casa ou cuidar das crianças, você tem que fazer as duas coisas junto...Você tem que saber o horário que toma banho, horário pra almoçar, pra trocar fralda, e limpar a casa, fazer almoço, é uma dona-de-casa...tem que deixar tudo limpinho, trocadinho...

A: A coisa nova [como diarista] é perguntar como que ela [patroa] gostaria que fizesse o serviço. Porque cada um tem um jeito de fazer... Por onde você quer que eu começo, pelo quarto, pelo quintal...cada um tem um jeito de fazer...Se sabe o seu lugar mas você precisa de uma orientação da patroa para não contrariar ela porque não é tua casa...Então você tem que fazer "à moda da patroa". O que gosta de passar nos móveis, o que não gosta, você dá uma opinião das experiências que eu tive durante esses anos todos de serviço, o que é bom pra limpar o vidro, o que é bom pra limpar o piso, o que é melhor pra limpar o box do banheiro...Entendeu? Mas aí é com o tempo, primeiro dia que você entra você faz "à moda da patroa". Depois que você estiver lá 1 mês, $2 \ldots$ ai "Olha fulana, tava pensando em passar isso...se a mancha vai sair..." ai você vai dando algumas dicas.

A: Vixe, perna no final do dia tem que dormir com os joelhos pra cima mais alto, porque as pernas e a coluna no final do dia já ta travada, ainda eu limpo lá, chego e eu limpo aqui...Esses dias eu me intoxiquei com um produto de limpeza...fui para no Hospital. 
B: Não, veja...principalmente o seguinte! Quando não é o trabalho doméstico, por exemplo, olha...ela estava lá hoje, mas eu não estou lá! Aqui, geralmente, na maioria das vezes, você também tem o mesmo risco, mas porém, você está aí... E quando você tem uma diarista mesmo aquela que tem a mensalista - , em algum momento, ela não está lá! Então, é uma pessoa que se as pessoas fossem avaliar direito, deveria ser muito mais bem avaliado. Por que? Você está convivendo com uma pessoa, que passa a fazer parte da sua vida - mais da vida, da família! Estou dizendo de uma forma genérica, porque na maioria dos casos é isso. Então, ou seja, até talvez hoje, começou a surgir nos últimos tempos cooperativas e surgiram empresas que se responsabilizam pela pessoa.

B: Aconteceu [da diarista não poder ir] mas, ela arrumou uma forma de alguém ir no lugar dela. Mas é, do tipo, se acontecer dela não poder ir mesmo, o que eu vou fazer? Eu vou ter que arrumar alguém pra pelo menos limpar a casa. Não é que eu não consigo, eu consigo! Mas se não tiver jeito eu vou fazer. Mas eu digo, o tempo, esse tempo que eu vou ficar lá, custa muito pra mim aqui. Então é melhor eu não fazer. Porque se eu ficar cuidando disso lá, o custo pra mim aqui é muito maior...então eu fiquei lá fazendo o trabalho doméstico, eu vou lavar roupa ou limpar o chão, alguma coisa do gênero...Mas, e aqui? Aqui que eu faço aqui, eu preciso arrumar um substituto...Seja lá, ou seja cá...No seu trabalho A ou no B, porque tudo é trabalho!

\section{Mudanças entre a rotina de mensalista para diarista}

A: A carteira é o vínculo empregatício, você não faz seu horário, você tem que fazer o horário certo...você tem que cumprir aquele horário, vamos supor das $8 \mathrm{~h}$ às $17 \mathrm{~h} . .$. então eu resolvi não trabalhar mais com esse método, porque eu ganho mais como faxineira...O salário ta $\mathrm{R} \$ 880,00$ reais...então eu vou ter que trabalhar de segunda à sexta, das $8 \mathrm{~h}$ as $17 \mathrm{~h}$, registrada, pra ganhar $\mathrm{R} \$ 800,00$ e poucos reais...Eu ganho $\mathrm{R} \$ 800,00$ da clínica, mais o que eu ganho por fora...

A: A questão é o seguinte! Você trabalha sem o vínculo, você faz seu horário, mas se você não for...você não ganha! Que nem na sexta eu perdi $\mathrm{R} \$ 150,00$. Porque de manhã eu trabalho no apartamento da dona da clínica eu ganho $\mathrm{R} \$ 50,00$, que eu termino em 2 horas de tão pequenininho que é...mais $\mathrm{R} \$ 100,00$ que eu trabalho da $13 \mathrm{~h}$ às $19 \mathrm{~h} 30,20 \mathrm{~h} . .$. Então eu perdi $\mathrm{R} \$ 150,00 \ldots$

A: Só que é cansativo, dói o corpo...que nem hoje, eu tava com dor na coluna. Tive que pedir uma massagem na cama, tem que deixar os pés pra cima, tem que deitar e ficar quietinha. $\mathrm{E}$ eu já fiz a cirurgia de varizes, e eu fiz a cirurgia achando que ia melhorar...Mas pelo contrário, piorou...As dores hoje são maiores...Então eu vivo à base de remédio de dor. Paracetamol, Dipirona...tudo que você imaginar desses remédios eu já tomei.

A: Ta aumentando o número de diaristas porque o custo de vida ta caro demais e você não tem esse vínculo com patrão. Que nem, você não tem obrigação de cuidar do filho deles, você não tem obrigação de cuidar do filho deles, criança é problema da mãe ou da babá, quem tiver cuidando lá...Então você não tem esse vínculo. Sem conta que todas essas mudanças que o governo fez para melhorar a vida da empregada doméstica, na verdade piorou...porque, muitas patroas mandaram a fixa embora, e ficaram só com a diarista...Preferiu coloca o filho no 
"Bezerra [de Menezes - colégio particular]" ou em creche paga e colocar uma diarista no lugar...

\section{Análise das entrevistas}

Aqui representamos a fala de uma das diaristas entrevistas como "A", e os argumentos de "B", empresário dono de uma franquia de restaurantes na cidade de Marília (SP). A e B não possuem vínculo um com o outro, A tem seus clientes assim como B contrata semanalmente uma diarista para limpeza geral de sua casa, lavar e passar sua roupa. Os dois entrevistados foram aqui selecionados por representarem os dois extremos da relação empregador(a) e diarista a ser discutida adiante.

A promessa de receber um maior salário em um espaço de tempo mais flexível é o atrativo do trabalho para diaristas. Ter carteira assinada pode comprometer a disposição para outros trabalhos por representar o vínculo com uma 'casa de família'. Contudo, a remuneração - e consequentemente - e o valor que esse trabalho possui passa pelas questões históricas retratadas aqui no início do texto.

Diante da temática do valor do trabalho doméstico remunerado, podemos compreender pelas falas de A qual o lugar de uma diarista na casa. O valor que seu trabalho possui tem a ver com a flexibilidade do contrato e ao mesmo tempo, seu descarte caso a pessoa para quem trabalha encontrar oferta mais em conta.

Como cita Marina Maluf (1995, p.202) o trabalho doméstico quando realizado com tanta destreza tende a parecer invisível a quem não tem a manutenção da casa em mente como suas obrigações . No caso, a autora refere-se ao mundo mental dos homens, mas a situação revela não só a relação entre papéis masculinos e femininos atualmente, como também, o fato de mulheres desconsiderarem o trabalho doméstico quando oferecido como um serviço por outras mulheres

Neste atrito, a fala de B reconhece o valor do trabalho doméstico de acordo com a demanda de sua casa, e a resume como uma 'necessidade'. O peso entre seu trabalho fora de casa e o serviço oferecido para a manutenção de seu domicílio é avaliado pelo 'custo' que ambos possuem. Trabalhar em casa com as demandas domésticas tem um rendimento menor financeiramente do que em seu trabalho como empresário, aqui essas atribuições lembram o valor que o trabalho servil passa em nossa sociedade, algumas famílias são servidas por terceiros e não por seus membros familiares. 
A diferença entre poder ou não poder ter uma empregada doméstica ou diarista é apresentado como uma questão salarial. O custo do trabalho de B em seu estabelecimento é alto, porém seu rendimento e comprometimento com horários é o bastante para que não tenha tempo de fazer o serviço doméstico, o qual 'da a oportunidade de outra pessoa ter esse trabalho'.

A remuneração também é estipulada de acordo com um valor usualmente proposto por empregadores. Todavia, quando observamos o tempo gasto de uma diarista para ganhar o dia, imaginamos - de acordo com a lógica apresentada por B - que A possa desembolsar um valor para outra pessoa realizar o trabalho doméstico em sua casa por gastar em média de 11 a 12 horas por faxina. Se B gasta em média 1 hora de seu dia para as demandas da casa, e pelo menos de 13 a 14 horas para seu estabelecimento, A e B trabalham quase o mesmo tanto de horas em quantidade, mas comparados a uma escala valorativa de trabalhos, A faz um tipo de serviço muito menos rentável que $\mathrm{B}$, e nossa questão aqui é, que para a sociedade brasileira em geral esse não é um trabalho gratificante financeiramente.

A função que uma diarista exerce em uma casa pode ser comparado ao papel que historicamente é atribuído às mulheres (ÁVILA\&FERREIRA, 2014, p.61). Para A, o trabalho concentra-se nas tarefas propostas pelo dono(a) da casa, a adequação aos gostos foi representado pela expressão "à moda da casa", que da título a este artigo e, ao mesmo tempo, insinua a ideia de um serviço entregue a domicílio mediante o pagamento.

Além das demandas da casa, muitas vezes a responsabilidade que uma diarista possui vai além do serviço doméstico, B reconhece a importância de ter como auxiliar uma mulher que acaba atendendo recados em seu lugar quando não está em casa. Entretanto, caso houver a ausência da diarista, o entrevistado exalta a possibilidade de fazer sazonalmente as demandas da casa, mas desde que esse trabalho não interrompa seu serviço principal. De certa maneira, o trabalho doméstico aparece como uma obrigação secundária, fácil de ser resolvido diante de tantos utensílios domésticos, mas para quem não possui 'tempo', é relegado às horas vagas perante outro trabalho mais rentável.

Essa contradição entre o tempo do empregador(ora) e o tempo da diarista - que pode ser estendido também à mensalista em certos casos - tem consequências para a definição de labor, ou traduzindo o contexto para a obra de Hannah Arendt (2010), para o desprendimento do tempo do empregador: 
[...] todas as eras anteriores à era moderna, ao identificarem a condição do trabalhador com a escravidão, tinham em mente precisamente esses criados domésticos, esses habitantes do lar, oiketai ou familiares, que trabalhavam em vista da mera subsistência e eram necessários para o consumo isento de esforço, e não para a produção. $\mathrm{O}$ que eles deixaram atrás de si em troca do que consumiam foi nada mais nada menos que a liberdade, ou, na linguagem moderna, a produtividade potencial de seus senhores. (ARENDT, 2010, p.107)

A forma precária com que muitas diaristas tem encarado o trabalho doméstico como um serviço mais rentável tem seus efeitos, como afirmamos, no corpo, na saúde e na subjetividade dessas mulheres trabalhadoras, e a tendência, como afirma A, é um aumento cada vez maior do número de diaristas, pelo comodismo de flexibilidade e descarte para empregadores(oras). A única garantia que pode existir neste vínculo acontece quando há um tempo maior de convivência entre ambas as partes.

Ao longo da entrevista com B que não consta aqui no texto, foi reconhecido o valor que a atual diarista que trabalha em sua casa há 5 anos possui, o mérito é retribuído por um valor - não informado - acima do convencional pago por 'faxina'. A medida, entretanto, não exime a necessidade de sua diarista ter que trabalhar em outras casas para ter uma renda acima de um salário mínimo ${ }^{3}$.

Algumas das questões levantadas no início do texto são respondidas com os argumentos dos entrevistados. O que muda de um regime de trabalho mensalista para diarista?

Além da frequência e rendimento, a flexibilidade do trabalho de diaristas é marcado pelos limites do corpo, do esforço físico e da saúde da trabalhadora doméstica. A ausência do vínculo compensa a liberdade de poder fazer seus próprios horários, mas ao mesmo tempo, o trabalho de 'extra' - entendido como uma renda a mais, mas que em situações de necessidade financeira passa a ser a fonte principal de sustento - também é caracterizado pela precariedade das condições de trabalho, a mudança traz novas possibilidades para trabalhadoras domésticas mas ao mesmo tempo acentua as discrepâncias entre classes sociais.

O paradoxo entre ganho diário e saúde do corpo é representado pela perda de pagamento caso a diarista não comparecer ao serviço combinado no dia. Em resumo, essa rotina é fragmentada em diversas casas por dia para que o montante no final da semana possa valer a pena. Como cita Arendt (2010), o trabalho tem uma conotação heróica pelo esforço que demanda, mas esconde o exercício de manutenção da própria vida:

(...)O emprego medieval da palavra trabalho, travail, arebeit, revela uma conotação similar de feito heroico que exige grande força e coragem e é realizado com espírito de luta. Mas a luta que o corpo humano trava diariamente para manter limpo o mundo e evitar-lhe o declínio tem pouca semelhança com feitos heroicos; a persistência que ela requer, para que se repare novamente a cada dia o esgotamento de ontem, não é coragem, e o que torna o esforço tão doloroso não é o perigo, mas a implacável repetição. Os 'trabalhos' de Hércules têm em comum com todos os grandes feitos o fato de serem únicos; mas, infelizmente, é somente o estábulo mitológico de Augias que fica limpo depois de despendido o esforço e realizada a tarefa. (ARENDT, 2010, p.124)

Essa mudança está para todas as casas que possuem empregadas domésticas?

Em outra entrevista - além de A e B -, uma das empregadas domésticas relatou ter deixado de fazer 'faxina' para ser admitida com carteira assinada em uma 'casa de família'. A

\footnotetext{
${ }^{3}$ Em 2016, o valor do salário mínimo era estipulado em $\mathrm{R} \$ 880,00$.
} 
inversão de expectativas é interessante, pois a experiência que tivemos em campo já havia proporcionado a oportunidade de conhecer também outros casos de empregadas que possuiam uma relação estável com os donos da casa onde trabalhavam. O tempo de serviço e, talvez um dos diferenciais que caracterizam a profissão, os auxílios, faziam parte dessa estabilidade.

A realidade atual não permite fazer um paralelo direto entre passado e presente quanto à profissão, mas delineia características simbólicas sobre essa relação. A proximidade com os donos da casa também é uma das características que Sandra Graham (1992, p.61) retrata ao falar de 'criadas' na região metropolitana do Rio de Janeiro na segunda metade do século XIX. Essa seria uma ponte também para a proteção de seus senhores, pertencer a uma casa era distinto de pertencer à rua, o contraste entre ambos é distinguido pela autora pelos perigos que o espaço público poderia oferecer, como furtos, roubos e homicídios.

A autora Jurema Brites (2000), em sua etnografia do trabalho doméstico remunerado em Vila Velha - Espírito Santo -, acrescenta mais detalhes referente à questão acima a ser respondida. A proximidade com empregadores pode ser interessante quando ocorre o que a autora chama de "fluxo de trocas materiais" (2000, p.103). O auxílio, simbolizado pelas trocas materiais - em alguns casos até imateriais, como prestação de serviços, conceder o nome para contratos imobiliários - faz o trabalho doméstico remunerado mais rentável que o salário pode condicioná-lo.

Portanto, a estabilidade para empregadas mensalistas tem seus efeitos no salário fixo recebido todo o final ou começo de mês, a certeza possibilita planejamentos. Contudo, dificilmente encontramos casos em que não havia algum auxílio a mais, mesmo quando representado por acréscimo no pagamento, o qual era associado a adjetivos de bondade e solidariedade de empregadores.

\section{Considerações finais}

Será que essas mudanças afetariam as representações do trabalho doméstico remunerado, seu vínculo e condições de trabalho relacionados a sua historicidade?

A representação em questão remete à historicidade da profisssão, e mesmo entre empregadas domésticas e diaristas foi possível perceber uma fala recorrente que fazem analogia entre o trabalho doméstico atual e o exercido durante o período escravista. A fala é ícone dos desdobramentos históricos e o valor que a profissão possui no país, hoje com mais 
reconhecimento que em seu passado, mas que ainda assim tenta se desvencilhar de obstáculos ocasionados pelas próprias relações sociais que estão inseridas, entre empregadores e empregadas/diaristas.

Aqui esboçamos comparações entre passado e presente, mas sabemos que há diferenças que foram superadas - como o reconhecimento legal da profissão, a exigência da carteira assinada - enquanto outras persistem ao tempo - a divisão sexual do trabalho doméstico, a baixa renda e grande informalidade contratual ainda são importantes para entender sua condição de trabalho.

Para compreender a resposta dessa pergunta voltamos ao conceito de 'trabalho reprodutivo' (ÁVILA\&FERREIRA, 2014). O valor que os “cuidados” ou "atividades de manutenção da casa e filhos" passa por elementos simbólicos de nossa cultura, principalmente por estar atrelado à família como uma instituição, historicamente mulheres estiveram a frente dessa responsabilidade, independente de classe e cor, mas o trabalho doméstico remunerado parece assegurar as estruturas de desigualdade quando tratados a partir das diferenças de classe. Ou seja, o "trabalho reprodutivo" quando oferecido como um serviço reflete o mesmo valor que ele possui quando é exercido sem remuneração.

De um modo geral, esse ato perpetua a estrutura da divisão sexual do trabalho doméstico, pois mesmo não sendo uma esposa, mãe, 'dona de casa', responsável pela manutenção domiciliar, essa obrigação fica a cargo de outra mulher, marcada por um perfil que atende aos indicadores sociais de classe e raça.

O status, enquanto elemento distintivo das hierarquias sociais de classe, raça e gênero, reconhecido na formação da sociedade brasileira a partir da família aristocrática, instituição esta baseada na mão de obra servil para a sua manutenção do lar, não representa mais diretamente a realidade do trabalho doméstico hoje, contudo, não deixou de quebrar com as dualidades apontadas ao longo do texto, entre "mando-obediência", "patrão-empregado" e "esnobe-humilde".

Portanto, a mudança de regime de trabalho de mensalistas para diaristas pode significar uma dinâmica diferente para os costumes de uma casa, não ser servido cordialmente todos os dias obriga seus moradores a tomarem determinadas responsabilidades, como foi demonstrado pelo entrevistado B, no entanto, este processo tem se mostrado mais como um avanço na precarização dessa categoria profissional do que um suspiro de modernidade. 
A 'casa de família' perde espaço para os clientes da 'faxina', sinônimo de habilidade de diaristas entre organizar sua agenda e seu esforço físico, mas essas mudanças de fato irão ocorrer quando houver uma transição estrutural do modelo familiar em que não só homens e mulheres, como diversos gêneros assumirem as demandas domésticas como de importância intransferível, e não terceirizado.

\section{Referências Bibliográficas}

ARENDT, Hannah. A Condição Humana. Rio de Janeiro: Editora Forense Universitária, 2010.

AULETE, Caldas. Novíssimo Aulete dicionário contemporâneo da língua portuguesa. GEIGER, Paulo (org.). Rio de Janeiro: Lexikon, 2011.

ÁVILA, Maria Betânia e FERREIRA, Verônica. Trabalho produtivo e reprodutivo no cotidiano das mulheres brasileiras. In: ÁVILA, Maria Betânia e FERREIRA, Verônica (org.) Trabalho Remunerado e Trabalho Doméstico no cotidiano das mulheres. Instituto Patrícia Galvão. Recife: SOS Corpo, 2014.

AZERÊDO, Sandra. A ânsia, o sino e a transversalidade na relação entre empregadas e patroas. Cadernos Pagu (19) 2002: pp.323-334.

BRITES, Jurema. Afeto, desigualdade e rebeldia: bastidores do emprego doméstico. Tese de Doutorado, Universidade Federal do Rio Grande do Sul, 2000.

BRUSCHININI, Cristina. Trabalho Doméstico: inatividade econômica ou trabalho nãoremunerado? Revista Brasileira de Estudos Populacionais, São Paulo, v.23, n.2, p. 331353, jul/dez. 2006.

BRASIL, Constituição (1988). Emenda Constitucional nº72, de 2 de Abril de 2013. Altera a redação do parágrafo único do art. $7^{\circ}$ da Constituição Federal para estabelecer a igualdade de direitos trabalhistas entre os trabalhadores domésticos e os demais trabalhadores urbanos e rurais. In: Constituição da República Federativa do Brasil. Disponível em: <http//www.planalto.gov.br/ccivil_03/constituição/emendas/emc/emc72.htm> Acesso em: $09 / 08 / 2017$

BURKE, Peter. O que é História Cultural?. Tradução de Sérgio Goes de Paula. Rio de Janeiro: Zahar, 2008.

DAMATTA, Roberto. Sabe com quem está falando? Um ensaio sobre a distinção entre indivíduo e pessoa no Brasil. In: Carnavais, Malandros e Heróis: para uma sociologia do dilema brasileiro. Rio de Janeiro: Rocco, 1997.

O que faz do Brasil, Brasil? Rio de Janeiro: Rocco, 1986.

Paulo: Brasiliense, 1985.

A casa e a rua. Espaço, cidadania, mulher e morte no Brasil. São 
DELICATO, C. Sobre lugares e trilhos: vivendo "acima" e "abaixo" da linha. Tese de Doutorado apresentada à Faculdade de Filosofia e Ciências - Universidade Estadual Paulista Campus de Marília, 2011, pp. 253.

DIAS, Maria Odila Leite da Silva. "Mulheres sem história". In: Revista de História, no 114, Jan/Jun, 1983, PP. 31-45.

Paulo: Editora Brasiliense, 1984.

Quotidiano e Poder em São Paulo no século XIX. São

DIEESE. O Emprego Doméstico nos anos 2000. In: Departamento Intersindical de Estatística e Estudos Socioeconômica. A situação do trabalho no Brasil na primeira década dos anos 2000. São Paulo: DIEESE, 2012.

DUARTE, Nestor. A ordem privada e a organização política nacional: contribuição à sociologia política brasileira. São Paulo: Companhia Editora Nacional, 1939.

FREYRE, Gilberto. Casa Grande \& Senzala. 51ª ed. São Paulo: Editora Global, 2006.

GEERTZ, Clifford. A Interpretação das culturas. Rio de Janeiro: Editora LTC, 2012.

GRAHAM, Sandra Lauderdale. Proteção e Obediência: Criadas e seus Patrões no Rio de Janeiro 1860 - 1910. São Paulo: Companhia das Letras, 1992.

HIRATA, Helena \& KERGOAT, Danièle. Novas Configurações da divisão sexual do trabalho. Cadernos de Pesquisa, v. 37, n. 132, p. 595-609, set./dez. 2007. Tradução de Fátima Murad.

Helena. Gênero, Classe e Raça - Interseccionalidade e Consubstancialidade das relações sociais. In: Tempo social, Revista de Sociologia da USP, v. 26, n. 1, 2014.

HOLANDA, Sérgio Buarque. Raízes do Brasil. Rio de Janeiro: José Olympio Editora S.A, 1982.

IBGE - Instituto Brasileiro de Geografia e Estatística. Síntese dos Indicadores Sociais 2016. Rio de Janeiro: IBGE, 2016.

KOFES, Suely. Mulher, Mulheres: a relação entre patroas e empregadas domésticas. A identidade nas armadilhas da diferença e da desigualdade. Campinas: Editora da Unicamp, 2001.

MALUF, Marina. Ruídos da Memória. São Paulo: Editora Siciliano, 1995.

PEDRO, Joana Maria \& SOIHET, Rachel. A emergência da pesquisa da História das Mulheres e das Relações de Gênero. In: Revista Brasileira de História. São Paulo, v. 27, no 54, p. 281-300, 2007.

PNAD, Pesquisa Nacional por Amostra de Domicílio. Instituto Brasileiro de Geografia e Estatística, IBGE, 2011.

SAFFIOTI, Heleieth. O Emprego Doméstico e Capitalismo. Petropólis: Vozes, 1978. 
SCOTT, Joan. Gênero: uma categoria útil de análise histórica. In: Educação e Realidade. Porto Alegre, Faculdade de Educação/UFRGS, v. 20, n. 2, p. 71-100, jul./dez. 1995.

TELLES, Lorena Féres da Silva. Libertas entre sobrados: Contratos de trabalho doméstico em São Paulo na derrocada da escravidão. Dissertação de Mestrado. São Paulo, USP, 2011.

VIANNA, Hermano. O mundo funk carioca. Rio de Janeiro: Jorge Zahar Editor, 1988.

\section{Site consultado}

IBGE - Instituto Brasileiro de Geografia e Estatísticas. Brasília/DF. Disponível em: http://www.cidades.ibge.gov.br/xtras/home.php Acesso 09/08/2017.

Recebido em:Julho de 2017

Aprovado em :Dezembro de 2017 